\title{
Determinants of Agricultural Technology Adoptions and Its Impacts on Productivity: A Case Study of Potato Producer Smallholder Farmers in Masha Woreda, Sheka Zone, SNNPR, Ethiopia. Household Level Analysis
}

\author{
Alebachew Angelo ${ }^{1} \quad$ Yilkal Wase $^{2} \quad$ Negese Tamirat $^{2}$ \\ 1. Masha Woreda Revenue Authority, Sheka Zone, SNNPR, Ethiopia \\ 2.Department of Economics, Jimma University, Jimma, Ethiopia
}

\begin{abstract}
The study was conducted in Masha district, Sheka Zone, Southern National Regional and peoples Region (SNNPR). Five potato producing kebeles from potato producing kebeles of Masha district were selected and a total of 251 selected households were interviewed to generate primary data 2018/19. The objective of the study was to evaluate the impact of improved seed and fertilizer on potato productivity in Masha district. Descriptive statistics and econometrics model were employed to achieve the objective. Multiple linear regressions were employed to determine factors that influence the adoption behavior of potato production technology of farmers and propensity score matching (PSM) techniques were applied to evaluate the impact of improved seed and fertilizer on potato productivity. A sum of 12 independent variables for the multiple linear regressions was used, out of which 7 variables were found to significantly influence the adoption of potato production technology. These are: size of land the household owned, family size, access to extension agent visit, soil fertility, age square, price of fertilizer and age farm household. The study recommends that any effort in promoting potato production technology should consider the social, economic, institutional and psychological characteristics for better adoption of potato production technology.
\end{abstract}

Keywords: Fertilizer, Impact, Multiple linear regressions, Propensity Score Matching, Potato

DOI: $10.7176 / \mathrm{FSQM} / 94-05$

Publication date: February $29^{\text {th }} 2020$

\section{Background of the Study}

Ethiopia is an agrarian country where more than $80 \%$ of the total population depends directly or indirectly on agriculture. Accelerating agricultural growth in Ethiopia has wide-ranging impacts beyond smallholder farmers and rural development. Agricultural sector contributes $35.8 \%$ of the country's GDP, $74 \%$ of all exports, provides raw materials for $70 \%$ of industries and employment for $72.74 \%$ of the population, directly or indirectly [1]. The agricultural technology and improved practices play a key role in increasing agricultural production and improving national food security in Ethiopia. Adoption of agricultural technology is not as such a long history in which traditional farming practices are still dominant in the farming system. The economic growth strategy of Ethiopia formulated in 1991, places high priority for accelerating agricultural growth and poverty alleviation by increasing yield with support of packages of technology that includes improved seed, fertilizer, and better management. Merely small number of farmers used improved varieties of crops, fertilizer, and farming practices in a limited area [2].

Agricultural productivity plays vital role to achieve food security and poverty reduction for the nation. Productivity enhancement helps to improve the living standard of smallholder farmer who live in major areas of the nation. Adopting agricultural technology has considerate impact on the improvements of the livelihood of farming community. One of the strategies to meet the increasing food demand is boosting the production within a limited resource through the adoption of improving farming inputs. Adopting agricultural technology (like improved seed and fertilizer) will be one of the basic instruments to enhance the living standard of farming community [3]. However, there was no empirical evidence on the determinants of farmers' adoption of Potato (improved seed and fertilizer) and its impact on productivity Masha Woreda. Consequently, it is important to describe the existing adoption level, identify the factors that determine adoption of improved seed and fertilizer and evaluate such a technology on potato productivity. Unlike other Studies [4\&5], done on determinants of adoption, current study will fill the gap by analyzing the intensity and impact of improved seed and fertilizer and impact on productivity thereby providing useful information, bridge the existing knowledge gap and helps to enhance the success of potato crop production. Therefore, the main focus of this study was to assess the impact of improved seed and fertilizer on potato productivity in Masha Woreda. Specifically, the objectives of the study were to identify factors that affect adoption of improved seed and fertilizer technology in potato cropping and evaluate its impact on potato productivity in the study area.

Production is basically an activity of transformation, which connects factor inputs and outputs. In economics, the Cobb-Douglas production functional form of production functions is widely used to represent the relationship 
of an output to inputs. Charles Cobb and Paul Douglas considered a simplified view of the economy in which production output is determined by the amount of labor involved and the amount of capital invested. In its most standard form for production of a single good with two factors, the function is $\mathrm{Y}=\mathrm{AL}^{\beta} \mathrm{K}^{\alpha}$. Where: $\mathrm{Y}=$ total production (the real value of all goods produced in a year or 365.25 days), $\mathrm{L}=$ labor input (the total number of person-hours worked in a year or 365.25 days), $\mathrm{K}=$ capital input (the real value of all machinery, equipment, and buildings), $\mathrm{A}=$ total factor productivity and your usual depreciation by utility in day after, $\alpha$ and $\beta$ are the output elasticity of capital and labor, respectively. These values are constants determined by available technology. Output elasticity measures the responsiveness of output to a change in levels of either labor or capital used in production, ceteris paribus. For example, if $\alpha=0.45$, a $1 \%$ increase in capital usage would lead to approximately a $0.45 \%$ increase in output. Sometimes the term has a more restricted meaning, requiring that the function display constant returns to scale, meaning that doubling the usage of capital $\mathrm{K}$ and labor $\mathrm{L}$ will also double output $\mathrm{Y}$, this holds if $\alpha+\beta=1$, If $\alpha+\beta<1$, returns to scale are decreasing, and if $\alpha+\beta>1$, returns to scale are increasing.

The existence of technologies can make huge difference and shift upward farmers yield frontier in grain production. The right type of fertilizer, at required quantities and at right time for a given crop is used fertilizers do generally increase productivity of crops. Understanding of the factors underlying farmers' decisions of whether or not to adopt agricultural technologies (such as improved seed and fertilizer) is crucial in terms of achieving enhanced crop yield through improved adoption of such technologies. There is a growing body of literature focusing on determinants of and impact of farmers' choice of technological adoption $[4,5,6,7,8,9,10,11,12$, $13,14,15,16 \& 17]$. In particular, numerous studies have been conducted focusing on the small farm household and institutional aspects of adoption decisions and their impact of improved seed and fertilizer. The literature has focused on specific potato cultivation; their studies were significant on potato productivity.

\section{Research Methodology}

The study was conducted in Masha Woreda, located in the Southern Nations Nationalities and Peoples Region (SNNPR) of Ethiopia. In this study, both primary and secondary data sources were used. Discussion with group of potato producer of improved seed and fertilizer was done to generate information. Key informants were also used as information source from different actors. A multi stage sampling procedure was used to select the kebeles and sample youth unemployment. A multi-stage probability sampling procedure was employed so as to reach the selection of a sample of smallholder farm households in the study. In the first stage: Out of the total of 3 Woredas of Sheka Zone, Masha Woreda were purposively selected, because of its high potential for potato production, and introduction and application of modern agricultural technology level of potato production. In the second stage, take into account the resource available, from 10 kebeles, 5 kebeles were selected based on their agro-ecological zone compared to the remaining 10 kebeles of the Masha Woreda. In the third stage: A total sample size 251 smallholder farmers were selected from each stratum using proportionate selecting procedures. The sample respondents from five kebeles would be selected randomly by employing random sampling method. The sample size was determined based on the formula by [18]. The data was collected from December 2019 up to April 2019 for five months.

In this study, descriptive statistics (percentage, frequency and mean) were mainly used. The descriptive analysis was conducted using Statistical Package for Social Science (SPPS). Cobb-Douglas production function was incorporated to analyze relationships between a dichotomous dependent variable and independent variables. Cobb-Douglas production function was used to understand the major factors that affect the productivity can be expressed as:

$\mathrm{Q}=\mathrm{f}(\mathrm{x}, \mathrm{z})$

$\mathrm{Y}=\mathrm{Ax}_{1}{ }^{\mathrm{a} 1} \mathrm{x}_{2}{ }^{\mathrm{a} 2}+\ldots \ldots \ldots \ldots \ldots+\mathrm{xn}^{\mathrm{an}} \mathrm{e}^{\beta 1 \mathrm{D} 1+\beta 2 \mathrm{D} 2+\beta \mathrm{nDn}+\mathrm{Ui}}$

This nonlinear function can be converted to linear function through simple logarithmic transformation and can be written as;

$\ln Y=\ln A+a_{1} \ln x_{1}+a_{2} \ln x_{2}+\ldots \ldots+a_{n} \ln x_{n}+\beta_{1} D_{1}+\beta_{2} D_{2}+\ldots+\beta_{n} D_{n}+U i$.

Therefore, the derived multiple linear models from the above function which can be used for this study are such form and specified as;

Lnoutput $=\beta_{0}+\beta_{1} \operatorname{lnFs}+\beta_{2} \operatorname{lnLs}+\beta_{3}$ Age $+\beta_{4}$ Age $^{2}+\beta_{5}$ Droad $+\beta_{6}$ Input $_{\mathrm{i}}+\beta_{7}$ pricefert $_{\mathrm{i}}$ $+\beta_{8}$ priceimp $_{i}+\beta_{9}$ Educ $_{i}+\beta_{10}$ soilfert $_{i}+\beta_{11}$ Rainfall $_{i}+\beta_{12}$ Acc $+\beta_{13}$ Aeav $+U_{i} \ldots \ldots$ (4)

Where, $\ln$ is a logarithmic function, Output $=$ potato output per hectare, $F s=$ number of family size household farmers have and $\mathrm{Ls}=$ size of land the farm household owned. Input $\mathrm{i}_{\mathrm{i}}=$ inputs for potato, $\mathrm{i}$, is indicated by numbers from $0 \ldots 3$ where 0 , indicates none users of both fertilizer and improved seed, 1 indicates for fertilizer users only 2 indicates improved seed users only, 3 both improved seed and fertilizer users for their potato production. Pricefert $_{i}=$ price of fertilizer, $i$, indicated by numbers from $0 \ldots 2,0$ indicates house hold farmer perceive the price of fertilizer is low, 1 for moderate and 2 for high. Priceimp $p_{i}=$ price of improved seed, i, indicated by numbers from $0 \ldots 2,0$ indicates house hold farmer perceive the price of improved seed is low, 1 for moderate and 2 for high. Age $=$ age of farm household head: Educ $_{\mathrm{i}}=$ educational level of household head, i, is indicated by numbers from $0 \ldots 4$, 
0 for illiterate, 1 traditional school (meserete-tmihrt and from religious institution), 2 for elementary, 3 for junior school and 4 for high school and above. Droad = distance of farm from main car road. soilfert $=$ soil fertility of household's farm area used for potato production, $i$, is indicated by numbers from $0 \ldots 2$, where 0 indicates household who have poor fertile soil according to his perception, 1 for moderate and 2 for highly fertile soil. Rainfall $_{\mathrm{i}}=$ rain fall character in the study area, $\mathrm{i}$, is indicated by numbers from $0 \ldots .2,0$ indicates rainfall is adequate in the study area, 1 for high, 2 for shortage rainfall. Acc = access to agricultural input credit, 1 for yes, 0 otherwise. Aeav $=$ access of agricultural extension agent visit, 1 for yes, 0 otherwise. $U_{i}=$ the error term of the model. Thus $\beta_{0}$ is intercept, $\beta_{1} \ldots \ldots \beta_{10}$ is coefficient of continuous variables and $\beta_{11} \ldots B_{12}$ is coefficient of dummy variables. PSM was employed in order to capture the impact of improved seed and fertilizer in enhancing the productivity of potato. In this study, the main pillar of Propensity score matching (PSM) is use of seed and fertilizer to potato productivity. The main importance of PSM is to clearly compare the productivity difference users of improved seed and fertilizer and users of traditionally better seed from farm area during harvest time and who do not use fertilizer. [19], can be explained PSM as the conditional probability of taking a treatment given pretreatment characteristics of the small farm households. Therefore, $\mathrm{Y}_{i}^{\mathrm{T}}$ and $\mathrm{Y}_{\mathrm{i}}^{\mathrm{C}}$ are the outcome variable who used at least improved seed or fertilizer and who didn't use this technology respectively. The difference in outcome between users and non-users can be expressed:

$\Delta \mathrm{Y}_{\mathrm{i}}=\mathrm{Y}_{\mathrm{i}}^{\mathrm{T}}-\mathrm{Y}_{\mathrm{i}}^{\mathrm{C}}$....

$\mathrm{Y}_{\mathrm{i}}^{\mathrm{T}}$ : Outcome of the user household, if he/she used the technology, $\mathrm{Y}_{\mathrm{i}}^{\mathrm{C}}$ : Outcome of non-user household, when he/she didn't used the technology, $\Delta \mathrm{Y}_{\mathrm{i}}$ change in the outcome as a result of using the technology for their $\mathrm{i}^{\text {th }}$ household. Then the formula for Average treatment effect on treated (ATT) can be seen as follow:

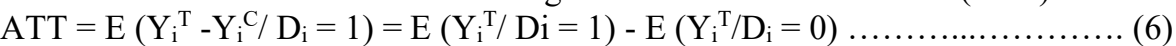

$\mathrm{E}\left(\mathrm{Y}_{\mathrm{i}}^{\mathrm{T}} / \mathrm{D}_{\mathrm{i}}=1\right)$ : mean outcomes of who used improved seed and fertilizer, $\mathrm{E}\left(\mathrm{Y}_{\mathrm{i}}^{\mathrm{C}} / \mathrm{D}_{\mathrm{i}}=0\right)$ : mean outcome of household, who do not used improved seed and fertilizer. The Average Effect of Treatment on the Treated (ATT) for the users and non-users sample households as is given by:

$\operatorname{ATT}=\mathrm{E}\left(\mathrm{Y}_{\mathrm{i}}^{\mathrm{T}}-\mathrm{Y}_{\mathrm{i}}^{\mathrm{C}} / \mathrm{D}_{\mathrm{i}}=1\right)=\mathrm{E}\left(\mathrm{Y}_{\mathrm{i}}^{\mathrm{T}} / \mathrm{D}_{\mathrm{i}}=1\right)-\mathrm{E}\left(\mathrm{Y}_{\mathrm{i}}^{\mathrm{C}} / \mathrm{D}_{\mathrm{i}}=1\right)$

According to [19], there are two basic assumptions to determine importance of outcome variable such as Conditional Independence Assumption (CIA) which excludes the familiar dependence between dependent variables.

$\left(\mathrm{Y}_{\mathrm{i}}^{\mathrm{T}}-\mathrm{Y}_{\mathrm{i}}^{\mathrm{C}}\right) \perp\left(\mathrm{D} / \mathrm{X}_{\mathrm{i}}\right)$

Assumption of Common Support which indicated that $\mathrm{P}(\mathrm{x})$ lies between 0 and 1 , and this restriction indicated that the test of the balancing property is performed only on the observations whose PSM fall to the common support region of the PSM of used and non-used [20].

$0<\mathrm{P}(\mathrm{X})<1$

\section{Results and Discussion}

\subsection{Respondents Background}

Table 1 presents the summary statistics of the sample households by use fertilizer and improved seed for their potato productions. About $85(33.86 \%)$ of the total small farm households didn't use fertilizer and improved seed. Households used fertilizers only were about 92(36.65\%), improved seed only 13(5.18\%) and household who used both fertilizer and improved seed 61 (24.3\%) during 2018/19 cropping season.

Table 1: Sample farm households by using improved seed and fertilizer

\begin{tabular}{lclc}
\hline \hline Variables & Attribute & frequency & Percent \\
\hline \multirow{3}{*}{ Inpputs P } & None user & 85 & 33.86 \\
& Fertilizer user & 92 & 36.65 \\
& Improved seed user & 13 & 5.18 \\
Total & Both fertilizer and improved seed user & 61 & 24.30 \\
\hline
\end{tabular}

Source: Computed from own survey data (2019)

\subsection{Factors Affecting Productivity of Potato}

The linear regression model of the agricultural productivity of farm household indicates that most variables were statistically significant such as: inputs used for potato, age of the household headed, price of fertilizer, family size of the household, size of land owned by household, soil fertility status of the household and access to extension visit are found to be the determinants of the agricultural productivity of farm household.

Input for potato: The regression result reveal that, there is a significant farm household productivity difference between fertilizer user, improved seed user, both fertilizer and improved seed user and non-user household. As compared to non-users, farm household who uses 1 unit of fertilizer input can increase their productivity of output by $0.56 \%$, concise with [11]. The use of improved potato for their production by 1 unit can increase the productivity 
of output by $0.79 \%$ as compared to non-users. Also using both fertilizer and improved potato for production by 1 unit increases the productivity of output marvelously by $0.92 \%$ from non-user.

Age: The regression model reveals that age of household head negatively and the square of age of household head was positively determines the productivity of potato. The result indicates that old farmers had higher agricultural output than the young farmers.

Price of fertilizer: The result of the regression model showed that the price of fertilizer has significantly affect productivity of potato and it has a negative sign. Implying that as compared to the farm household who perceive the price of fertilizer is lower, the productivity of the farmer's output/ha for who perceive the price of fertilizer is moderate is decreased by $0.44 \%$, when farm household's perception of price for fertilizer increases by 1 unit. The second case indicates the productivity of the farmer's output/ha who perceive the price of fertilizer is high is decreased by $0.65 \%$, when farm household's perception for a price of fertilizer increases by $1 \%$ as compared to the farmer who perceives the fertilizer is lower.

Land size: More specifically, size of land owned by farm household was a significant contribution for the positive change of output productivity during period of analysis; as the size of land area owned by household increases by 1 percent, the productivity of output increases by $0.3 \%$.

Family size: Surprisingly, as the number of household member increases by 1 the productivity of output/ha for the household increases by $0.37 \%$ and it is also significant at $1 \%$. Because large and productive family size increases potato production through proper labor division for wedding and harvest time. This is because to reduce the time rate for land preparation as well as to increase the frequency of cultivation to controls weeds, large number of labor is needed. The large number of labors is come from large families. Therefore, farm households who have large number of families are more opportune than small families to increase potato productivity.

Extension agent visit: Another finding of regression was access of extension visit was statistically significant at $1 \%$ and $5 \%$. The result reveal that as compared to farm household who didn't get extension service during one production season, having an access of extension service in a given one production period increases by 1 unit the productivity of output/ha of household increases by $0.34 \%$.

Soil fertility: The fertility of soil significantly and positively influences potato productivity of farm household. Farmers' producing on medium and highly fertile soil was more productive than farmers' operating on poor soil fertility. As compared to poor soil fertile the farm households have, to have a medium fertile and highly fertile soil increases productivity of potato by $0.29 \%$ and $0.39 \%$ respectively. This result reveals that there is an opportunity to increase potato productivity through improved and available fertile soil. Therefore, improvements and soil fertility management practice options with respective agro-ecology and soil types can contribute some impact in increasing potato productivity.

Table 2: Estimation result of potato production technology adoption linear regression

\begin{tabular}{|c|c|c|c|c|c|c|c|}
\hline Lnoutput & Attribute & Coef. & $\begin{array}{l}\text { Robust } \\
\text { Std. Err. }\end{array}$ & $\mathrm{T}$ & $\mathrm{P}>|\mathrm{t}|$ & [95\% Conf. & Interval] \\
\hline \multirow[b]{3}{*}{ InpputsP } & 1 & .5642771 & .1319683 & 4.28 & 0.000 & 3042252 & .824329 \\
\hline & 2 & .8024348 & .2433748 & 3.30 & 0.001 & .3228494 & 1.28202 \\
\hline & 3 & .9299269 & .2173587 & 4.28 & 0.000 & .5016077 & 1.358246 \\
\hline \multirow[b]{2}{*}{ Pricefert } & 1 & -.451615 & .1263604 & -3.57 & 0.000 & -.7006162 & -.2026139 \\
\hline & 2 & -.6563904 & .1143481 & -5.74 & 0.000 & -.8817205 & -.4310603 \\
\hline \multirow[b]{2}{*}{ Priceimp } & 1 & -.1753706 & .1928067 & -0.91 & 0.364 & -.5553084 & .2045673 \\
\hline & 2 & -.1239698 & .1908038 & -0.65 & 0.517 & -.4999608 & .2520213 \\
\hline Lnfsize & - & .3688342 & .1069645 & 3.45 & 0.001 & .1580539 & .5796144 \\
\hline Age & - & -.0684681 & .0285522 & -2.40 & 0.017 & -.124732 & -.0122041 \\
\hline Age square & - & .0006445 & .000266 & 2.17 & 0.031 & .0000598 & .0012293 \\
\hline \multirow{4}{*}{ Educ } & 1 & .0364668 & .2151831 & 0.17 & 0.866 & -.3875652 & .4604989 \\
\hline & 2 & -.2506907 & .1574656 & -1.59 & 0.113 & -.5609868 & .0596053 \\
\hline & 3 & .0008179 & .1620025 & 0.01 & 0.996 & -.3184182 & .3200541 \\
\hline & 4 & .0587576 & .1676122 & 0.35 & 0.726 & -.2715329 & .3890481 \\
\hline \multirow{4}{*}{ Droad } & 2 & .0648326 & .0968026 & 0.67 & 0.504 & -.125923 & .2555882 \\
\hline & 3 & -.0012076 & .1100038 & -0.01 & 0.991 & -.217977 & .2155618 \\
\hline & 4 & .0539346 & .1701281 & 0.32 & 0.752 & -.2813137 & .3891828 \\
\hline & 5 & .3738239 & .2034748 & 1.84 & 0.067 & -.027136 & .7747839 \\
\hline Lnland & & .3067564 & .0697228 & 4.40 & 0.000 & .1693633 & .4441496 \\
\hline \multirow[b]{2}{*}{ Soilfert } & 1 & .2853269 & .1133931 & 2.52 & 0.013 & .0618785 & .5087753 \\
\hline & 2 & 3847668 & .1195803 & 3.22 & 0.001 & .1491262 & .6204074 \\
\hline \multirow[t]{2}{*}{ Rainfall } & 1 & -.0789282 & .088372 & -0.89 & 0.373 & -.2530707 & .0952144 \\
\hline & 2 & -.0670326 & .2366857 & -0.28 & 0.777 & -.5334368 & .3993715 \\
\hline
\end{tabular}




\begin{tabular}{|l|c|c|c|c|c|cc|}
\hline Lnoutput & Attribute & Coef. & $\begin{array}{c}\text { Robust } \\
\text { Std. Err. }\end{array}$ & $\mathrm{T}$ & $\mathrm{P}>|\mathrm{t}|$ & {$[95 \%$ Conf. Interval $]$} \\
\hline Access to credit & - & -.0272336 & .0918902 & -0.30 & 0.767 & -.208309 & .1538419 \\
\hline Extension acc & - & .3457038 & .1249569 & 2.77 & 0.006 & .0994684 & .5919392 \\
\hline Cons & - & 4.101715 & .7167546 & 5.72 & 0.000 & 2.689304 & 5.514125 \\
\hline
\end{tabular}

Source: Computed from own survey data (2019)

Where, * significant level at 10\%, ** significant level at 5\% and *** significant level at $1 \%$. Number of obs $=191$, LR $\operatorname{chi}^{2}(12)=156.26$, Prob $>$ chi $2=0.0000$, Log likelihood $=--61.060754$ and Pseudo $\mathrm{R}^{2}=0.5613$

\subsection{Propensity score matching model Regression Result}

Propensity score matching model was used to analyze the impact of agricultural technology adoption on potato productivity. According to [21] the necessary steps when implementing propensity score matching is: Propensity Score estimation, choose matching algorithm, check overlap/common support and testing matching quality. The main criterion for estimating the common support region is to delete all observations whose PSM is lower than the minimum PSM of treat and higher than the maximum in the control [22]. Therefore, household farmers whose propensity scores between 0.02780567 and 0.94210717 were not considered for matching purpose. PSM algorithm can be selected based on its own criteria: balancing test, Pseudo R-square (low), matched sample size (large) and LR chi-square (insignificant), the algorithm which are selected from four matching algorithms: nearest neighbor matching (NNM), radius matching (RM), caliper matching, and kernel matching (KM). Accordingly, a nearestneighbor matching method with of 2 was found to be the best estimator of the data of potato productivity. The propensity score matching models revealed, after controlling the pre-intervention difference of the adopters and none adopters of fertilizer and improved seed, productivity difference of users signifies by $49.21 \%$ or 63.34 quintal/ha variation than none users. After estimating propensity score matching and approximating the above randomized experiment and reducing selection bias, there is still a significant productivity difference between users and none users. Therefore, the PSM result showed that using agricultural technology (fertilizer and improved seed) has significant contribution in increasing agricultural productivity.

\section{Conclusion and Policy Implication}

The objective of this study was to evaluate the factor that influences technology adoption on potato productivity and determine its impact (using fertilizer and improved seed) on potato productivity. Descriptive and econometric model were employed to achieve the objective of the study. In particular, propensity score matching approach was used to compare adopter households with non-adopters. The study applied cross sectional household level data collected in 2017/2018 cropping season from 251 samples farming household head. The main factors influencing potato productivity technology are the family size household head, land size household head, soil fertility, access to extension agent visit and age square of household head, price of fertilizer and age of the farm household head. The results of propensity score matching model reveals that households who adopt (used both fertilizer and improved seed) for their potato production is better off in productivity of output; on average value of output generated per hectare by technology users were 128.54 quintal while 65.19 for non-users with having 63.34 quintal difference. This implies that using improved seed and fertilizer for potato production has a significant impact on potato productivity in the study area. Therefore, it is used to scaling up the best potato producing technology and practices of the adopters to other farmers can be considered as one option while introducing new agricultural practices and technologies is another option.

The improved access to diversified and qualified agricultural inputs still remains critically important. Therefore, local government with together regional should supply improved farm inputs on the time for farmers through creating awareness on recommended amounts. The agricultural research and extension activities need to consider additional agronomic practices along with the potato technology method in order to increase potato production, and for the successful promotion, adoption and scaling up of good agronomic practices and extension should contact farmers individually as well as in group to be awarded in terms of technology of potato is suitable to improve household income. It is better to work on household's perception on price of technology, especially on fertilizer price. This is because farm households who were rationally compare the expected output after technology use with respect to price of input they afford, and used this technology got better output than who frustrated for price from far and in silent to use. The introduction of the above measures into the picture of technology adoption, therefore, could enhance the number of adopters and the cropped area under fertilizer and improved seed of potato technology. Hence, expansion in the level of technology adoption would consequently result in substantial potato productivity and income on a sustainable basis.

\section{Reference}

1. NBE. (2017). Annual Report, Addis Ababa, Ethiopia.

2. Hailu, B. (2008). Adoption of improved tef and wheat production technologies in crop-livestock mixed 
systems in northern and western Shewa zones of Ethiopia (Doctoral dissertation, University of Pretoria).

3. Yitbarek, T. (2017). Factors affecting adoption of legume technologies and its impact on income of farmers: The case of Sinana and Ginir Woredas of Bale Zone (Doctoral dissertation, Haramaya University).

4. Birhane, G., Seme, D., \& Ibrahim, M. . (2004). Development and Application of Agricultural Technology in Ethiopia: A Discussion Paper. A discussion paper presented on the occasion of celebrating the 50th Anniversary of the establishment of the Alemaya Unive.

5. Kassu. (2009). Analysis of agricultural input supply system: the case of Dale Woreda, Southern Nations, Nationalities and Peoples' Region (Doctoral dissertation, Haramaya University).

6. Emana, B., Gebremedhin, H., \&Regassa, N . (2010). Impacts of improved seeds and agrochemicals on food security and environment in the Rift Valley of Ethiopia: implications for the application of an African Green Revolution.

7. Smale, M., Byerlee, D., \& Jayne, T. (2011). Maize revolutions in sub-Saharan Africa.The World Bank.

8. Okob. (2010). Improved inputs use and productivity in uganda's maize sub-sector. Economic policy research centre .

9. Kefyalew. (2010). Fertilizer consumption and agricultural productivity in Ethiopia.In In the Ethiopian Development Research Institute Working Papers, February 2011; Gebre-ab, N., Dorosh, P., Eds.; Ethiopian Development Research Institute (EDRI): Addis Ababa.

10. Saari. (2011). Production and Productivity as Sources of Well-being. MIDO OY, 25.

11. Endrias, G., Ayalneh, B., Belay, K. \& Eyasu, E. (2013). Productivity and Efficiency Analysis of Smallholder Maize Producers in Southern Ethiopia.Department of Agricultural Economics, Haramaya University. J Hum Ecol, 41(1): 67-75.

12. Admassu, T., Workneh N., Sisay A. Adugna L.,\& Bamlaku A. (2011). Does Farmer Field School Training Improve Technical Efficiency? Evidence from Smallholder Maize Farmers in Oromia, Ethiopia. International Journal of African Development, 3(1), 4.

13. Tesfaye, S., Bedada, B., \&Mesay . (2016). Impact of improved wheat technology adoption on productivity and income in Ethiopia.African Crop Science Journal, 24(s1), 127-135.

14. Mesfin. (2017). Adoption of improved chickpea technologies in North Gondar zone of Ethiopia: The case of Gondar Zuria District (Doctoral dissertation, University of Gondar).

15. Mustefa, B., Mulugeta T. \& Raja, K. P. (2017). Economic efficiency in maize production in Ilu Ababor zone, Ethiopia. Research Journal of Agriculture and forestry Vol. 5(12),1-8.

16. Girma \& Amanuel. (2017). Role of improved seeds towards improving livelihood and food security at Ethiopia. International journal of research, 5(2).

17. Juma, J., Zhou Y., Kwikiriza N., Ogutu S., Barker I., Schulte E., Atieno E. and Taj J. (2017). Productivity and food security effects of using of certified seed potato: the case of Kenya's potato farmers.

18. Yamane, T. (1967). Statistics, an Introductory Analysis, 2nd Ed., New York: Harper and Row.

19. Rosenbaum, P.R., and Rubin, D.B. (1983). The Central Role of the Propensity Score in Observational Studies for Causal Effects. Biometric, 70 (1): 41-55.

20. Becker, S. O., and A. Ichino. (2002). Estimation of Average Treatment Effects Based on Propensity Scores. the Stata Journal, 2(4), 358-377.

21. Grilli, Leonardo, and Carla Rampichini. (2011). Propensity scores for the estimation of average treatment effects in observational studies.46P.

22. Caliendo, M., \& Kopeinig, S. (2008). Some practical guidance for the implementation of propensity score matching. Journal of economic surveys, 22(1), 31-72. 